\title{
Economic Burden of Disability Adjusted Life Years (DALYs) of Injuries
}

\author{
Koustuv Dalal1,2*, Leif Svanström ${ }^{2,3}$ \\ ${ }^{1}$ Centre for Injury Prevention and Safety Promotion (CIPSP), School of Health \& Medical Sciences, Department \\ of Public Health Science, Örebro University, Örebro, Sweden \\ ${ }^{2}$ Department of Public Health Sciences, School of Life Sciences, University of Skövde, Skövde, Sweden \\ ${ }^{3}$ Division of Social Medicine, Department of Public Health Sciences, Karolinska Institute, Stockholm, Sweden \\ Email: ${ }^{*}$ koustuv2010@hotmail.com
}

Received 2 March 2015; accepted 20 April 2015; published 27 April 2015

Copyright $(2015$ by authors and Scientific Research Publishing Inc.

This work is licensed under the Creative Commons Attribution International License (CC BY).

http://creativecommons.org/licenses/by/4.0/

(c) (i) Open Access

\begin{abstract}
Economic burdens of injuries at the country level are unknown. In the current study we tried to explore the economic burden of DALYs loss due to injuries at the country level, then distributed according to the World Bank's income groups. Methods: Data from the World Bank and the World Health Organization websites were used. Disability adjusted life year (DALY) and gross domestic product (GDP) per capita were used to estimate the economic loss for RTIs. Estimates of economic burdens were presented in tables and figures. Results: The total economic loss of the world during 2004 by means of DALYs due to injuries was 613. 144 billion USD, corresponding value of 848.205 billion USD in 2014. DALYs burden of injuries were concentrated (almost 75\%) among low and lower middle income countries. Economic burdens of injuries were concentrated (over 80\%) among higher middle and high income countries. Iraq had lost almost one-fifth of its GDP due to injuries. The USA had the highest amount of economic loss for injuries (169.136 billion USD) among all countries. Conclusion: Injuries are highly expensive and they account for heavy losses to GDP. Injury prevention should be prioritized in order to save such losses to life and economies.
\end{abstract}

\section{Keywords}

Costs, DALYs, Injuries, Income Group

\section{Introduction}

Injuries are major health problems in every country in the world. Injuries have caused over 5 million deaths per

${ }^{*}$ Corresponding author. 
year, accounting for 16,000 deaths per day—slightly more than one person per hour [1]. According to the estimate of the World Health Organization's Global Burden of Disease Study, unintentional injuries resulted in more than 3.9 million deaths in 2004. Among the 15 - 29 years old of age group, road traffic injuries, drownings, burns, poisonings, falls and other unintentional injuries accounted for top five of the 15 leading causes of death [1]. The attention of policy makers, however, still lacks the necessary actions to control injuries and promote safety.

Worldwide, compared with fatal injuries, non-fatal injuries constitute the larger proportion of all injuries [2] [3]. Injuries cause individual, family and social problems by means of health, financial and socioeconomic issues, including medical and non-medical reasons, loss of productivity, disabilities and legal costs [2]. Younger groups are more affected by injuries which result in very high numbers of years lived with disabilities. The economic impacts of injuries are also very high as usually injuries occur in comparatively young healthy individuals [1]-[3]. Losing a breadwinner to injuries and/or death often results in huge economic burdens by pushing families into poverty, or poorer families deeper into poverty [4]. Injuries result in substantial economic costs to the victims, their family members and to the community as a whole. Therefore, injuries place an enormous burden on national economies. However, the evidence of the economic burden of injuries is not obvious according to the literature. The literature indicates that low income countries and poor people are more affected by injuries [1]-[3] [5]-[7]. However, the actual economic burdens of injuries at the national level are unknown. In the current study we have tried to explore the economic burden of disability adjusted life years (DALYs) due to injuries at the country level and then distributed at World Bank's income group levels. We have also presented the economic loss of DALYs due to injuries as percentage of respective country's GDP.

\section{Methods}

An injury is generally defined as the physical damage that results when a human body is suddenly or briefly subjected to intolerable levels of energy. Injury is the transfer of energy exceeding tissue tolerance limit [8]. Injuries are broadly categorized by unintentional injuries and intentional injuries. Unintentional injuries are caused by motorized transportation; unintentional falls; drowning; fire; burns; poisoning; animal and snake bites and other unintentional causes [5] [6]. Intentional injuries are caused by violence and war, suicide and self-inflicted injuries [9].

The disability adjusted life year (DALY) is a measure of health gap. DALYs "extends the concept of potential years of life lost due to premature death to include equivalent years of 'healthy' life lost by virtue of being in states of poor health or disability" [10]. DALYs are the sum of the years of life lost (YLL) due to premature mortality in the population and the years lost due to disability (YLD) for incident cases of the disordered health condition (DALY = YLL + YLD). One DALY represents the loss of one year of equivalent full health [10].

Injury and related DALYs data from World Health Organization (WHO) were explored in the current study. More details of data sources were appended in the global burden of disease: 2004 update by WHO [11]. Also data relating to the gross domestic product (GDP) for 2004 and per capita GDP 2004 for each of the WHO Member States were obtained from the World Bank [11]. DALYs used in the current study were not age-standardized. Two data sources (injury-DALYs data and GDP, per capita GDP data) were merged into a single database by member countries. The value of DALYs lost due to injuries was calculated by multiplying the estimated DALYs loss due to injuries in 2004 by the GDP per capita 2004 for the respective countries, using human capital approach [12]. Individuals are productive members of the economy. Individual's yearly economic contribution is the GDP per capita. Years lost due to disability or death are years that are not productive and not contributing in the GDP. Therefore, we have valued the individuals only as much as their contributions to their country's economy. In addition, the value of DALYs loss due to injury as a percentage of total GDP in 2004 was calculated for each country. Then we have calculated the total DALYs for each country individually, and summed by income group. Data presented in absolute term means the actual figures obtained from the original country level data. Also data were presented after normalization (log X, where X is GDP/Injury death/DALYs). Cost of DALYs was estimated after normalization of GDP \& GDP per capita and then multiplying by DALYs. More details of calculation of DALYs, data collection at country level were appended elsewhere [10]-[14].

There are in total 188 countries which have been included in the study according to the relevant data which were available from respective websites. All death and DALYs units are in units of 1000. Monetary values are expressed in USD (2004). To estimate current figures for the year 2011, a 3\% discount rate is employed. 


\section{Ethical Issue}

This paper has used country level published data from World Health Organization and World Bank. It does not deal with any individual or personal data. Therefore this study does not require any ethical permission.

\section{Results}

The total economic loss of the world during 2004, by means of DALYs due to injuries was 631.144 billion USD, corresponding to a value of 848.206 billion USD in 2014. The top ten countries accumulated almost 2/3rds (65.45\%) of the economic burden due to DALYs loss. The top 15 countries constituted 75\%, the top 20 countries constituted $81 \%$ and the top 25 countries constituted $85 \%$ of the total economic burden of the world due to DALYs loss. In absolute term, the USA had the highest economic loss due to DALYs resulting from injuries amounting to 169.136 billion USD (2004), which was equivalent to $1.43 \%$ of the USA GDP. The top ten countries with the highest economic burden (in absolute term) of DALYs loss due to injuries are presented in Figure 1.

However, after normalization of the GDP of the countries, a relative comparison demonstrate that top 10 countries for DALYs loss due to injuries are India, China, Nigeria, United States, Indonesia, Russia, Brazil, Pakistan, Bangladesh and Ethiopia (Figure 2).

Top ten countries for accumulating injury costs as percentage of own GDP (2004) by means of DALYs loss are Iraq (19.35\%), Somalia (9.78\%), Sri Lanka (8.82\%), Sudan (8.20\%), Cote d’Ivoire (7.53\%), Myanmar (7.20\%), Angola (6.98\%), Sierra Leone (6.53\%), The Russian Federation (6.51\%) and Colombia (6.30\%). Figure 3 represents the comparison of injury cost as a percentage of GDP and as a percentage of health expenditure of those ten countries. It is interesting to observe that majority of these ten countries have lower health expenditure than the cost of injury-DALYs as a percentage of GDP (Figure 3).

According to income groups, countries of the lower middle income group have the highest proportions of injury mortalities (60\%), the highest proportions of DALYs loss due to injuries (61\%) and less than one-fifth (18\%) of the proportions of economic value of DALYs in absolute term. Low income countries constitute $16 \%$ of DALYs loss due to injuries and only $2 \%$ of DALYs-based economic losses in the world (Table 1).

However, after normalization of GDP data, we have found that lower income countries have the highest proportions of injury mortalities (32\%), and one-fifth (21\%) of the proportions of economic value of DALYs. Lower middle income group has estimated almost one third injury mortalities (31\%), the highest proportions of

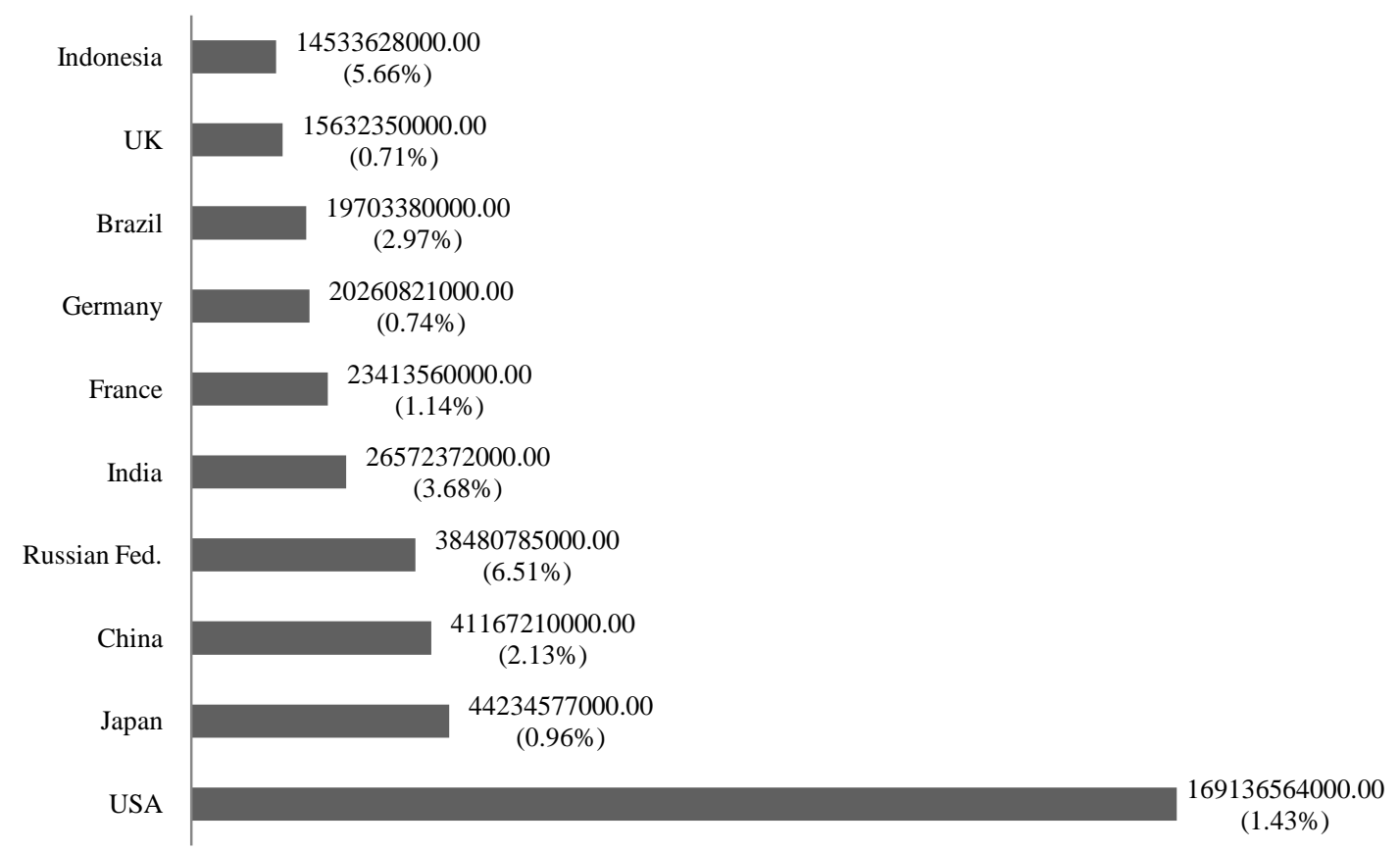

Figure 1. Economic burden of the top 10 countries for DALYs loss due to injuries in absolute term (amounts correspond to percentage of respective countries GDP, 2004). 


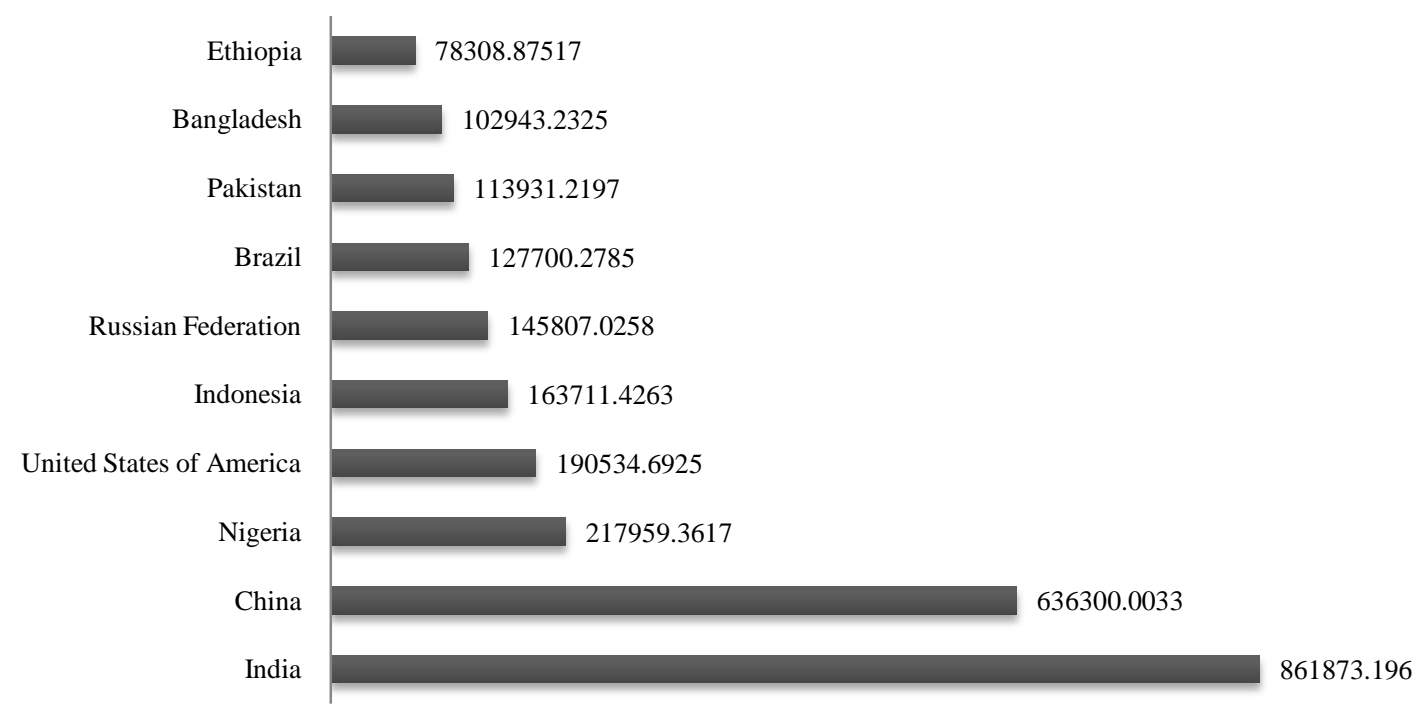

Figure 2. Economic burden of the top 10 countries for DALYs loss due to injuries after normalization of GDPs in USD.

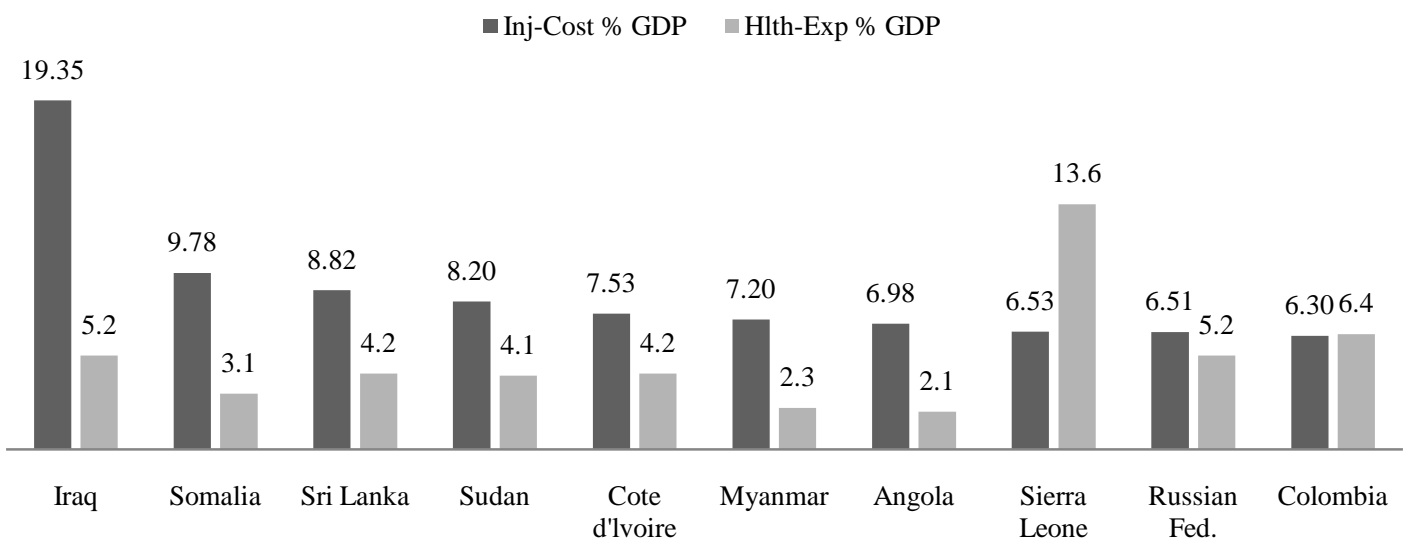

Figure 3. Comparison of economic loss of DALYs and health expenditure as a percentage of GDP for top ten countries, in accordance with economic loss of DALYs due to injuries as percentage of respective GDP (2004).

DALYs loss due to injuries (29\%) and 27 percent of the proportions of economic value of DALYs. High income countries have accounted for 16 percent injury deaths and 29 percent of the proportions of economic value of DALYs.

Within low income group countries, top ten countries have lost almost five to ten percent of their GDPs in economic loss due to injury-DALYs. Somalia has lost almost ten percent of its GDP. In the lower middle income group, Iraq has lost almost 20 percent of its GDP due to injury-DALYs. Sri Lanka has lost almost nine percent of its GDP. Russia is at the top of the list followed by Colombia and South Africa in the higher middle income group. Within high income countries, Saudi Arabia, Latvia and Estonia are the top three countries losing highest percentage of their GDP due to injuries. The top ten countries in each income group, accumulating the highest percentages of the economic loss in proportion to GDPs of these countries are presented in Table 2.

\section{Discussion}

During 2004, the total economic loss in the world by means of DALYs due to injuries was 613.144 billion USD, which was almost 10 times the amount received by all the countries as "Net official development assistance and official aid” by the World Bank in that year [13]. That means the money for such development is not functioning 
Table 1. Deaths due to injuries, estimated number of disability adjusted life years (DALYs) loss due to injuries, and estimated economic loss of DALYs by World Bank income groups, 2004.

\begin{tabular}{cccc}
\hline World Bank's Income Groups & $\begin{array}{c}\text { Death Due to Injuries } \\
\text { (Thousands) }\end{array}$ & $\begin{array}{c}\text { DALYs Loss Due to Injuries } \\
\text { (Millions) }\end{array}$ & $\begin{array}{c}\text { Economic Value of DALYs } \\
\left.\text { (Billion USD }_{2004}\right)\end{array}$ \\
\hline Absolute data & $761.9(13.20 \%)$ & $29.178(15.58 \%)$ & $10.503(1.66 \%)$ \\
Low income countries & $3490.3(60.46 \%)$ & $113.930(60.85 \%)$ & $115.429(18.29 \%)$ \\
Lower middle income countries & $961.7(16.67 \%)$ & $31.585(16.87 \%)$ & $125.718(19.92 \%)$ \\
Upper middle income countries & $559(9.68 \%)$ & $12.526(6.69 \%)$ & $379.495(60.13 \%)$ \\
High income countries & $5772.9(100 \%)$ & $187.219(100 \%)$ & $631.145(100 \%)$ \\
Total & & & $332.38(20.86 \%)$ \\
Normalized data & $40.09(32.05 \%)$ & $105.16(26.89 \%)$ & $429.16(26.94 \%)$ \\
Low income countries & $38.68(30.92 \%)$ & $113.36(28.99 \%)$ & $368.33(23.12 \%)$ \\
Lower middle income countries & $26.21(20.95 \%)$ & $84.28(21.55 \%)$ & $463.08(29.07 \%)$ \\
Upper middle income countries & $20.08(16.05 \%)$ & $88.17(22.55 \%)$ & $1592.95(100 \%)$ \\
\hline High income countries & $125.06(100 \%)$ & $390.97(100 \%)$ & \\
\hline
\end{tabular}

Table 2. Top 10 countries in each income group, ranking in accordance with economic loss of DALYs due to injuries as percentage of respective GDP (2004).

\begin{tabular}{|c|c|}
\hline World Bank’s Income Groups & Countries (Economic Loss as \% of Respective GDP) \\
\hline Low income countries & $\begin{array}{l}\text { Somalia (9.78\%); Myanmar (7.20\%); Angola (6.98\%); Sierra Leone (6.53\%); DR Congo } \\
\text { (6.21\%); Burundi (6.08\%); Liberia (5.93\%); Uganda (5.27\%); Central African Republic } \\
\text { (5.21\%) and Zimbabwe (4.94\%). }\end{array}$ \\
\hline Lower middle income countries & $\begin{array}{l}\text { Iraq (19.34\%); Sri Lanka (8.82\%); Sudan (8.20\%); Cote d’Ivore (7.53\%); Indonesia (5.65\%); } \\
\text { Yemen (5.31\%); Beliza (3.89\%); Nigeria (3.81\%); El Salvador (3.77\%) and India (3.68\%). }\end{array}$ \\
\hline Upper middle income countries & $\begin{array}{l}\text { Russian Federation (6.51\%); Colombia (6.30\%); South Africa (5.03\%); Kazakhstan (4.44\%); } \\
\text { Belarus (4.22\%); Venezuela (3.71\%); Lithuania (3.46\%); Dominican Republic (3.43\%) and } \\
\text { IR Iran (3.32\%). }\end{array}$ \\
\hline High income countries & $\begin{array}{l}\text { Saudi Arabia (3.15\%); Latvia (3.11\%); Estonia (3.03\%); Trinidad and Tobago (2.28\%); Poland } \\
\text { (1.76\%); Finland (1.72); Uruguay (1.70\%); Slovakia (1.59\%); Republic of Korea (1.58\%) and } \\
\text { Hungary (1.56\%). }\end{array}$ \\
\hline
\end{tabular}

as targeted due to huge loss caused by injuries. Therefore, world policy makers should immediately take stern action for injury prevention in all countries, irrespective of their income status. Low income countries are losing up to seven percent of their GDPs, lower middle income countries are losing 3 to 19 percent (China 2.13\%; India 3.68\%). United Nations agencies are advocating Millenium Development Goals (MDGs). However, they are not emphasizing injury prevention strongly enough.

In absolute term, high income countries have only a ten percent burden of injury deaths and a 60 percent burden of injury costs (compared with the world level). Lower middle income countries have a 60 percent burden of injury deaths and an 18 percent burden of injury costs (compared with the world level). Such anomalies can be explained as the economic costs of DALYs of injuries are based on GDP per capita and the findings are based on absolute terms. After normalization of the GDP data, we have found that India, China, Nigeria, United States, Indonesia, Russia, Brazil, Pakistan and Bangladesh are accumulating 55 percent of injury costs. DALYs are based on a fairness principle that considers “'like as like' within an information set comprising the health conditions of individuals, differentiated solely by age and sex" [13]. Therefore, in the current analysis, the estimation of DALYs-based cost of injuries in absolute term are also based on "like as like". Additionally, DALYs are the most widely used measures across countries and cultures [14]. The current estimation can be generalized as it is 
comparable and it is based on the most widely used measures such as DALYs and GDP.

Considering the economic burden of injuries as a percentage of GDP, the top ten countries are losing out significantly. Iraq has four times more economic loss due to injuries than health expenditure as percentage of GDP. During that phase (2004 and earlier) Iraq had a war situation. Therefore, the current study has also advocated against war since a huge amount of injury costs are drained out of the economy during wartimes.

The Commission on Macroeconomics and Health reported that each life year should be valued at roughly three times annual earnings [15]. In the current study we have not included adjusted estimates; rather we have tried to estimate actual income loss due to injury-DALYs. As there is no unanimous consensus upon such adjustment factors, the current estimation may underscore the enormous impact of injuries. The study may suffer from reporting biases, with a disproportionate underestimation of injuries. Reports from several countries in the study are from hospital-based death-reporting systems. It is worthwhile to mention that the economic value of years lost due to disability may differ from that for years of life lost due to premature mortality. For example, unlike the people killed as a result of a road traffic injury, persons who are disabled as a result of that road traffic injury may continue to contribute to national economy. Therefore, the results in the current study may overestimate the economic value of DALYs lost to road traffic injury. They undercounted deaths since injury mortality outside hospitals or health care facilities were not included [16]. Low and middle income countries have more chance of such under estimation [2] [17]. Therefore the actual burdens may be much more than the reported in the current estimations. There are numerous methodological challenges and data limitations. Several countries (CookIland, Nauru, Niue, Tuvalu) could not present appropriate data for injuries, resulting those countries to be excluded in the current study. The current study has focused on the issue through public health approach and used absolute value to inform the respective countries policy makers about the measurement of injury problems. However, the relative comparison using normalization of the GDPs has demonstrated almost the same trained, that is a higher proportion of economic burden for the high income countries. It is, however, important to quantify the economic burden of injuries at the global level, especially in low and middle income countries. To the best of authors' knowledge, this is the first attempt to estimate the global economic burden of injuries. However, future studies at the multi-country level with all cost elements will provide more in-depth view to the problem. Beside human capital approach at the gross level (by GDP), we can have national representative studies focusing on medical costs and non-medical costs. Though these sorts of nationally representative studies incur enormous resources, such studies can give us actual views of the injury problems for proper decision making.

Lower and upper middle income countries have huge burden of injuries, especially road traffic injuries [16]. Road traffic injuries not only affect the individuals and families by means of personal and economic losses but also affect country economy and health system facilities. Severe and fatal injuries require the best medical team support including trauma care facilities in effort to save lives [16]-[20]. Injury as a whole consumes a significant amount of resources. In the low and lower middle income countries injury treatments consume a very high proportion of individual resources mainly due to out-of pocket payment and societal resources [7] [16] [21] [22]. Additionally, there is a large gap between low and lower middle income countries and high income countries in the burden of injury, injury health care and related insurance systems affecting the poor more [23]. The current study indicates that especially for the low and lower middle income countries the economic cost of injuryDALYS are much higher than their GDP proportion of health care expenditures. This is an important finding indicating a big health care gap in those resource poor countries. However, unlike some diseases, injuries are preventable [1]. Evidence is available which suggests that some countries have reduced injury rates significantly through injury prevention and safety promotion programs such as Safe Community Programs [5] [6] [16] [24][26]. Safe Community Program has demonstrated significant cost-benefit ratio by implementing injury prevention and safety promotion principals at local level [26].

\section{Conclusion}

Injuries have enormous burden of disease in terms of morbidity, mortality and economic resources. Therefore, the World Health Assembly should deliberately emphasize injury control as being of utmost importance at local, regional and national levels.

\section{Conflict of Interest Statements}

Declared none. 


\section{Role of Funding Source}

None.

\section{References}

[1] WHO (2008) Violence, Injuries, and Disability: Biennial 2006-2007 Report. World Health Organization, Geneva.

[2] Peden, M., Oyegbite, K., Ozanne-Smith, J., Hyder, A.A., Branche, C., Rahman, A.F., et al. (2008) World Report on Child Injury Prevention. World Health Organization, Geneva.

[3] Krug, E.G., Sharma, G.K. and Lozano, R. (2000) The Global Burden of Injuries. American Journal of Public Health, 90, 523-526. http://dx.doi.org/10.2105/AJPH.90.4.523

[4] Dalal, K. and Jansson, B. (2007) Cost Calculation and Economic Analysis of Violence in Low-Income Country: A Model for India. African Safety Promotion: A Journal of Injury and Violence Prevention, 5, 45-56.

[5] Wang, S., Zou, J., Yin, M., Yuan, D. and Dalal, K. (2011) Injury Epidemiology in a Safe Community Health Service Center in Shanghai, China. Health Med, 5, 479-485.

[6] Lindqvist, K. and Dalal, K. (2012) The Impact of Child Safety Promotion on Different Social Strata in a WHO Safe Community. Journal of Injury and Violence Research, 4, 20-25. http://dx.doi.org/10.5249/jivr.v4i1.83

[7] Dalal, K. and Rahman, A. (2009) Out-of-Pocket Payments for Unintentional Injuries: A Study in Rural Bangladesh. International Journal of Injury Control \& Safety Promotion, 16, 41-47. http://dx.doi.org/10.1080/17457300802475992

[8] Robertson, L.S. (1998) Injury Epidemiology. 2nd Edition, Oxford University Press, New York.

[9] WHO (2002) World Report on Violence and Health. World Health Organization, Geneva.

[10] WHO (2002) Global Burden of Disease (GBD) 2002 Estimates: Incidence, Prevalence, Mortality, YLL, YLD and DALYs by Sex, Cause and Region, Estimates for 2002 as Reported in the World Health Reports 2003 and 2004. http://www.who.int/healthinfo/global_burden_disease/estimates_regional_2002/en/

[11] WHO (2004) Global Burden of Disease: 2004 Update. World Health Organization, Geneva.

[12] Weisbrod, B. (1961) Economics of Public Health: Measuring the Impact of Diseases. 2nd Edition, University of Pennsylvania Press, Philadelphia.

[13] Murray, C.J.L. and Acharya, A.K. (1997) Understanding DALYs. Journal of Health Economics, 16, 703-730. http://dx.doi.org/10.1016/S0167-6296(97)00004-0

[14] WHO (2012) Global Burden of Disease Concept. http://www.who.int/quantifying_ehimpacts/en/

[15] WHO (2001) Commission on Macroeconomics and Health. Report of the Commission on Macroeconomics and Health: Macroeconomics and Health: Investing in Health for Economic Development. World Health Organization, Geneva.

[16] Dalal, K., Lin, Z., Gifford, M. and Svanström, L. (2013) Economics of Global Burden of Road Traffic Injuries and Their Relationship with Health System Variables. International Journal of Preventive Medicine, 4, 1442-1450.

[17] WHO (2004) World Report on Road Traffic Injury Prevention. World Health Organization, Geneva.

[18] Bjerre, B. and Schelp, L. (2000) The Community Safety Approach in Falun, Sweden-Is It Possible to Characterize the Most Effective Prevention Endeavours and How Long-Lasting Are the Results? Accident Analysis \& Prevention, 32, 461-470. http://dx.doi.org/10.1016/S0001-4575(99)00058-5

[19] Zhang, L., Dalal, K., Yin, M., Yuan, D., Andrews, J. and Wang, S. (2012) The KAP Evaluation of Intervention on FallInduced Injuries among Elders in a Safe Community in Shanghai, China. PloS ONE, 7, e32848. http://dx.doi.org/10.1371/journal.pone.0032848

[20] Lindqvist, K. and Dalal, K. (2012) Impact of Social Standing on Traffic Injury Prevention in a WHO Safe Community. Health, 4, 216-221. http://dx.doi.org/10.4236/health.2012.44033

[21] Dalal, K. and Aremu, O. (2013) Fairness of Utilizing Healthcare Facilities and Out-Of-Pocket Payment Burden: Evidence from Cambodia. Journal of Biosocial Science, 45, 345-357. http://dx.doi.org/10.1017/S0021932012000521

[22] Davoudi-Kiakalayeh, A., Dalal, K., Yousefzade, C., Jansson, B. and Mohammadi, R. (2011) Costs Related to Drowning and Near Drowning in Northern Iran (Guilan Province). Ocean \& Coastal Management, 54, 250-255. http://dx.doi.org/10.1016/j.ocecoaman.2010.12.004

[23] Lao, Z., Gifford, M. and Dalal, K. (2012) Economic Cost of Childhood Unintentional Injuries. International Journal of Preventive Medicine, 3, 303-312.

[24] Guyer, B., Gallagher, S.S., Chang, B.H., Azzara, C.V., Cupples, L.A., et al. (1989) Prevention of Childhood Injuries: Evaluation of the Statewide Childhood Injury Prevention Program (SCIPP). American Journal of Public Health, 79, 1521-1527. http://dx.doi.org/10.2105/AJPH.79.11.1521 
[25] Svanström, L., Ekman, R., Schelp, L. and Lindström, A. (1995) The Lidköping Accident Prevention Programme-A Community Approach to Preventing Childhood Injuries in Sweden. Injury Prevention, 1, 169-172. http://dx.doi.org/10.1136/ip.1.3.169

[26] Zhao, Z. and Svanström, L. (2003) Injury Status and Perspectives on Developing Community Safety Promotion in China. Health Promotion International, 18, 247-253. http://dx.doi.org/10.1093/heapro/dag020 